\title{
The Analysis of the Pore Evolution of Ore Granular Media During Bacteria Heap Leaching Based on X-Ray Computerised Tomography
}

\author{
A.X. Wu Central South University, School of Resources and Safety Engineering, and University of Science \\ and Technology Beijing, School of Civil and Environment Engineering, China
}

B.H. Yang Central South University, School of Resources and Safety Engineering, and Hunan International Economics University, Department of Electricity and Information Engineering, China

S.H. Yin University of Science and Technology Beijing, School of Civil and Environment Engineering, China

Y.M. Wang Central South University, School of Resources and Safety Engineering, China

\begin{abstract}
The bacteria column leaching experiment of low grade sulphide ore was conducted and the ore granular media were scanned by X-ray computerised tomography scanner before and after leaching. Based on the image processing operation, the spatial distribution of the porosity, and the change of pore size distribution and connectivity before and after leaching were investigated. In addition, the mechanism of pore evolution during leaching was also analysed. The results indicate that the porosity, pore size and pore connectivity of the ore granular media during leaching all have spatial and temporal variability. After leaching, the porosity distribution along the column became more inhomogeneous and assumes a decreasing trend from top to bottom, especially the bottom zone, with porosity decreasing greatly. The amount of larger pores increased at the top and middle zones after leaching while decreased at bottom zone. The connectivity of the top and middle zone was improved but deteriorated at the bottom zone. The main mechanisms for pore evolution are the subsidence of the entire granular ore body and the transportation and accumulation of the fine particles, chemical precipitates and colloidal substance at local areas.
\end{abstract}

\section{Introduction}

Solution mining is one of the mining methods that uses some chemical solvent and microorganism to dissolve, leach and recover valuable metals in a deposit, ore heap or dump. This method has been researched and applied widely in China, particularly with heap leaching, which has become an effective and economical method of treating poor ore, tailings and waste ore for metals, such as uranium, copper, gold and silver, etc. The performance of a heap leaching system depends on two aspects: one is the dissolving ability of the solvent to available minerals; the other is the permeability of the ore heap which influences the fluid flow among the ore particles. These two aspects determine the recovery ratio and leaching rate of the available metals. During heap or dump leaching, physical, chemical and biological reactions occur in ore granular media under the role of solution and natural subsidence, dissolution, deposition and solute transfer occur as a result, so the pore network continues to evolve and has temporal and spatial variability. The physical parameters that represent the property of the ore granular media, such as porosity, pore size, pore connectivity, etc., will change. As a result, the permeability will be affected. Understanding the pore evolvement mechanism and its relationship with permeability of the packed ore bed is important to enhance the performance of heap leaching by optimising design and operation. However the conventional experimental method can only indirectly measure the macro-porosity, which is insufficient for us to understand the complex system.

In recent years, X-ray computerised tomography technology has been developed that provides the advantage of exploring the inner structure of research objects without any damage occurring to those structures. The technology has been applied widely in many scientific research fields. Combining the results of the tomography with digital image processing and visualisation, the entire process becomes more useful. One of the important fields of research is understanding the pore structure of porous media, such as soil, oil 
reservoirs and rock, etc. (Al-Raoush and Wilson, 2005; Hirono et al., 2003; Kamath et al., 1998; Ketcham and Carlson, 2001; Liu et al., 2005; Mecke and Arns, 2005; Nakashima et al., 2004; Pierret et al., 2002; Wildenschild et al., 2002). The applications of tomography in granular media are little reported (Wu et al., 2007), especially the ore granular media in heap leaching system, which are very complex and more difficult to understand. There are several researchers that have conducted such research, such as Lin et al. (2005). They have evaluated the porosity variety during bioleaching, but did not discuss the spatial distribution of pore size and connectivity, and did not analyse the mechanism of pore evolvement. In this regard, a more advanced CT scanner, SOMATOM Sensation 16, is used to scan the ore packed column in our research. The main purpose of this paper is to analyse the spatial and temporal variety of the porosity, pore size distribution and connectivity of ore granular media before and after bacteria heap leaching, and to explore the mechanisms of pore evolution.

\section{Experimental apparatus and methodology}

\subsection{Material and apparatus}

The ore sample used for the experiment is the copper sulphide ore provided by Dexing copper mine in Jiangxi province. The chemical phases of $\mathrm{Cu}$ in the ore sample are shown in Table 1 and the chemical compositions of the ore sample are shown in Table 2.

Table 1 The chemical phases of $\mathrm{Cu}$ in the ore sample (wt /\%)

\begin{tabular}{lccccc}
\hline $\begin{array}{l}\text { Chemical } \\
\text { phases }\end{array}$ & $\begin{array}{c}\text { Primary } \\
\text { copper sulfide }\end{array}$ & $\begin{array}{c}\text { Secondary } \\
\text { copper sulfide }\end{array}$ & $\begin{array}{c}\text { Free } \\
\text { copper-oxide }\end{array}$ & $\begin{array}{c}\text { Combined } \\
\text { copper-oxide }\end{array}$ & $\begin{array}{c}\text { Total amount } \\
\text { of copper }\end{array}$ \\
\hline Content of $\mathrm{Cu}$ & 0.46 & 0.02 & 0.0049 & 0.0037 & 0.49 \\
\hline
\end{tabular}

Table 2 The chemical composition of the ore sample (wt /\%)

\begin{tabular}{lccccccccc}
\hline Component & $\mathbf{C u}$ & $\mathbf{F e}$ & $\mathbf{S}$ & $\mathbf{M o}$ & $\mathbf{S i O}_{2}$ & $\mathbf{A l}_{\mathbf{2}} \mathbf{O}_{\mathbf{3}}$ & $\mathbf{C a O}$ & $\mathbf{M g O}$ & $\mathbf{A s}$ \\
\hline content & 0.490 & 4.050 & 2.320 & 0.030 & 60.750 & 13.800 & 3.360 & 2.800 & 0.015 \\
\hline
\end{tabular}

The leaching experimental apparatus is shown in Figure 1. The leaching column's height is $500 \mathrm{~mm}$ and its inner diameter is $64 \mathrm{~mm}$. In the external wall of the column, a tenuous iron wine is inlaid at heights of $10 \mathrm{~mm}, 280 \mathrm{~mm}$ and $450 \mathrm{~mm}$ respectively as the scanning mark. With these marks, the image at different heights can be located rapidly, which will help improve the efficiency of image processing.

The CT scanner used for scanning ore granular media in column is SOMATOM Sensation 16, shown in Figure 2. It combines multi-section images collecting technology, reconstruction technology and high speed of rotating as well. With high spatial density, it is sufficient to meet the requirement of image collection in this experiment. 


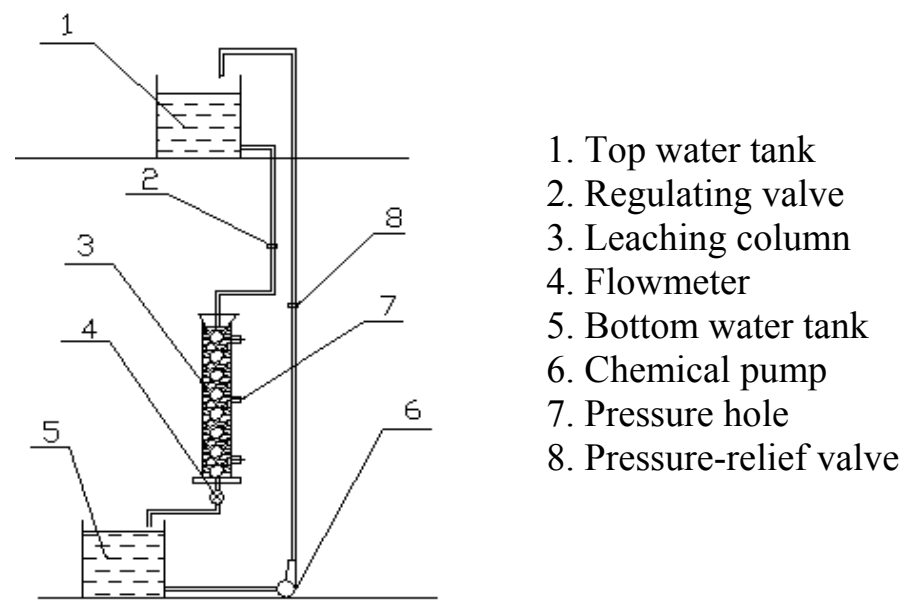

Figure 1 Schematic diagram of column leaching apparatus



Figure 2 X-ray CT scanner

\subsection{Experimental procedure}

The ore sample was first packed in the leaching column. Figure 3 shows the size distribution of the ore particles. In order to avoid wall effects, the largest size is about $10 \mathrm{~mm}$, which is one sixth of the inner diameter of the column. Before filling, it is necessary to spread some water on the ore particles and then mix them completely, so that segregation can be reduced. After filling, the column was scanned by the CT scanner with parameters of $120 \mathrm{KV}$ and $300 \mathrm{~mA}$ and the scan interval was set at $0.75 \mathrm{~mm} / \mathrm{scan}$. Then the bacteria leaching experiment was carried out. The adopted bacteria were Thiobacillus ferrooxidans, and the inoculation amount was $10 \%$. The solution application rate was set at $0.008\left(\mathrm{~m}^{3} / \mathrm{m}^{2} . \mathrm{h}\right)$ and the initial $\mathrm{pH}$ value was 2.0. The leachate passed through the column and was then pumped for re-circulation. During the leaching process, the height of the ore packed bed in the column, $\mathrm{pH}$ value, electric potential, bacteria concentration, seepage velocity, etc., were measured periodically. The total leaching time was 90 days. After leaching, the column was scanned again with the same parameters. In the end, about 680 and 660 crosssectional images were obtained for the whole ore particle packed bed before and after leaching. 


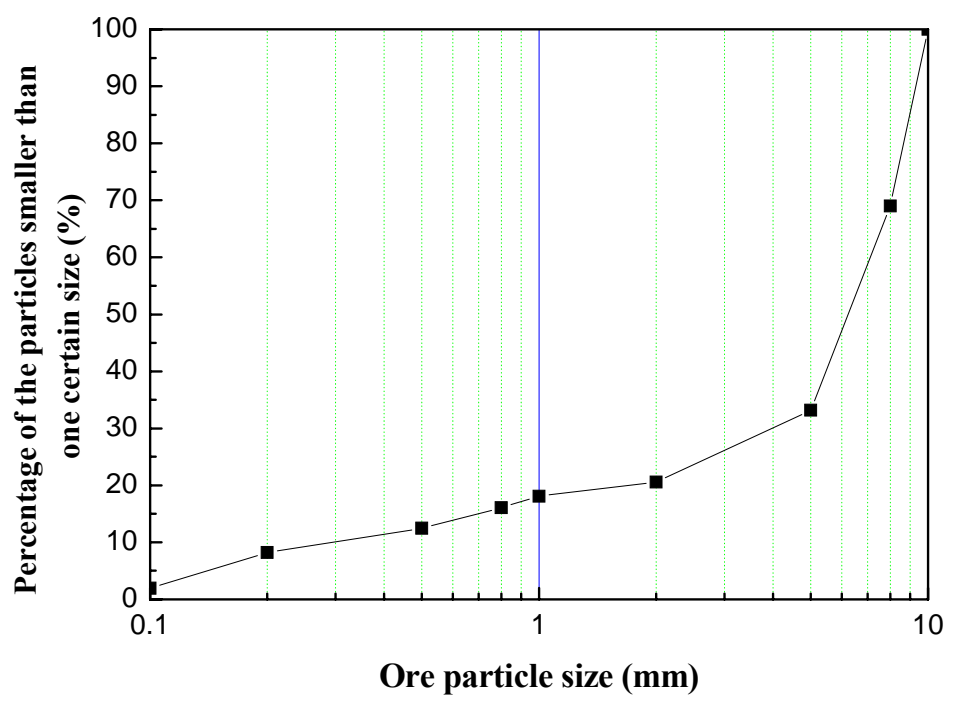

\section{Figure 3 Ore particle size distribution}

\section{Results and discussion}

\subsection{Porosity distribution}

The porosity of granular media is defined as the percentage of the volume of pores to the total volume. For the ore granular media in heap leaching, porosity is an important parameter for reflecting its leachability as it directly relates to the heap's permeability. Here, In order to quantify the porosities of ore granular media along the height of the column, it is necessary to preprocess the obtained original gray scale CT images. Just as shown in Figure 4, all of the cross-sectional images were transformed to binary image with the same threshold value so as to extract the pores. Since the grey scales of pores and ore particles are greatly different, so the Otsu method can be used to determine the threshold value. The pre-processing of the images and the calculation of porosity were all completed by programming based on Matlab.

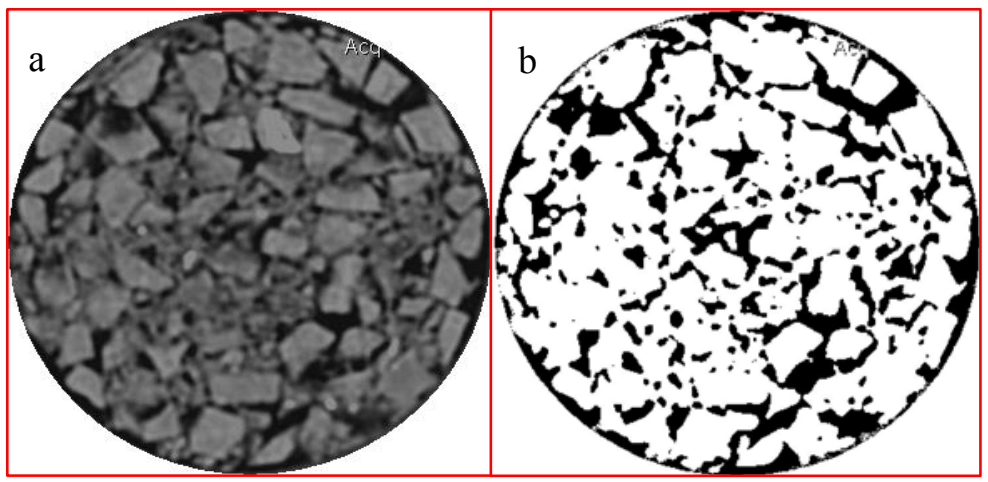

(a) Original grey scale CT image; (b) Binary image

Figure 4 Pre-processing the X-ray CT image

It can be seen from Figure 4(b) that porosity is the ratio of pores to the whole cross section. Namely, it is the ratio of pixel number of black area to the total pixel number of the whole cross section. Once the porosities of all sections were calculated, the curves of porosity distribution before and after leaching along the height of the column can be obtained, as shown in Figures 5 and 6. For each image, the right hand side is the longitudinal profile of the whole column. 


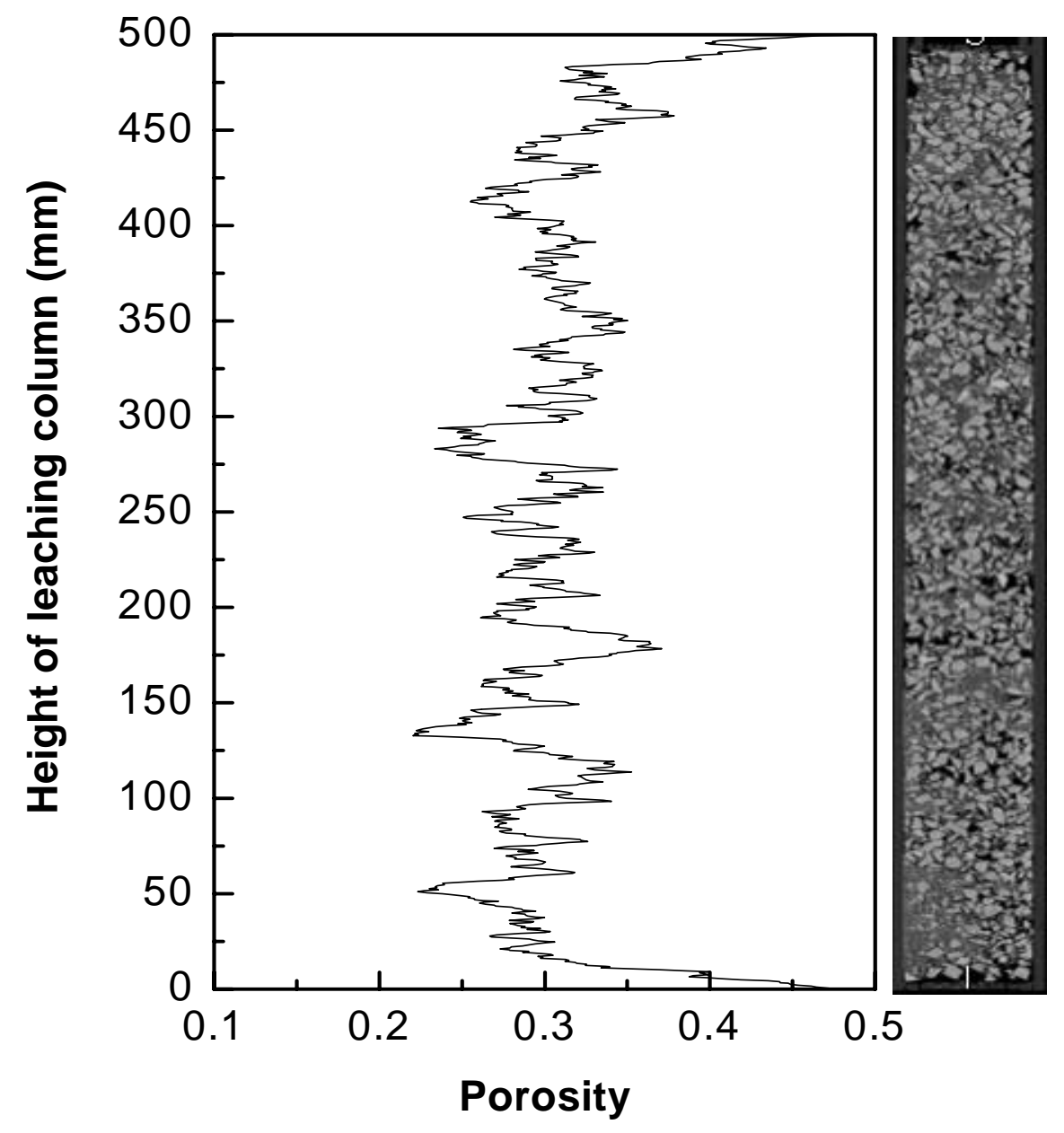

Figure 5 Porosity distribution before leaching

The porosity distribution curve in Figure 5 has lots of wave crests and hollows, which indicates that the porosity before leaching has spatial variability, distributing inhomogeneously from top to bottom. The porosities of some local areas increase or decrease suddenly. This is mainly due to the segregation caused by ore filling operation. The average porosity before leaching is $30.54 \%$ by calculation. See from Figure 6 , the wave crests and hollows in the porosity distribution curve are enhanced and the curve assumes an obvious decreasing trend from top to bottom. This indicates that the area with low porosity before leaching will be much lower after leaching; meanwhile the area with high porosity before leaching will be much higher. So the porosity distributes more inhomogeneously after leaching. The average porosity is $27.91 \%$ by calculation, which decreased by $2.63 \%$ over before leaching. Dividing the column into ten zones from top to bottom, the average porosity of each zone before and after leaching are calculated for comparison, shown in Figure 7. It is shown that in addition to some areas in the top zone, the porosities in other zones decreased after leaching, particularly the bottom zone, which decreased greatly. 


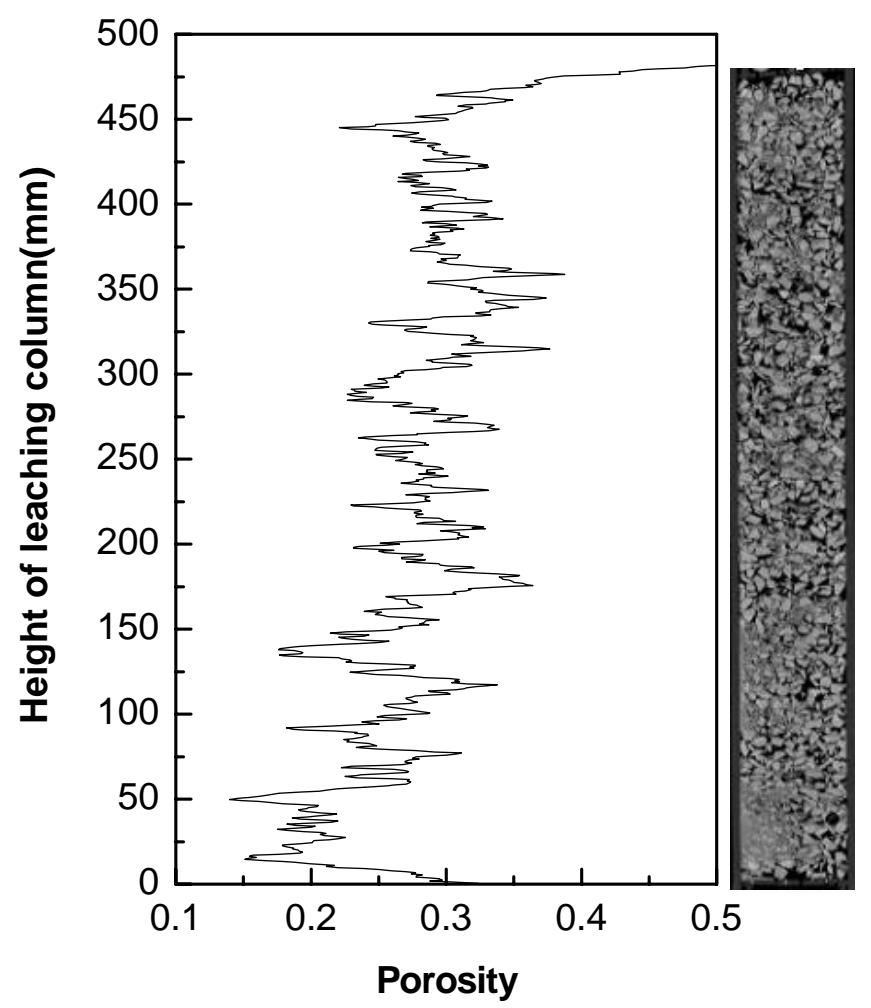

Figure 6 Porosity distribution after leaching

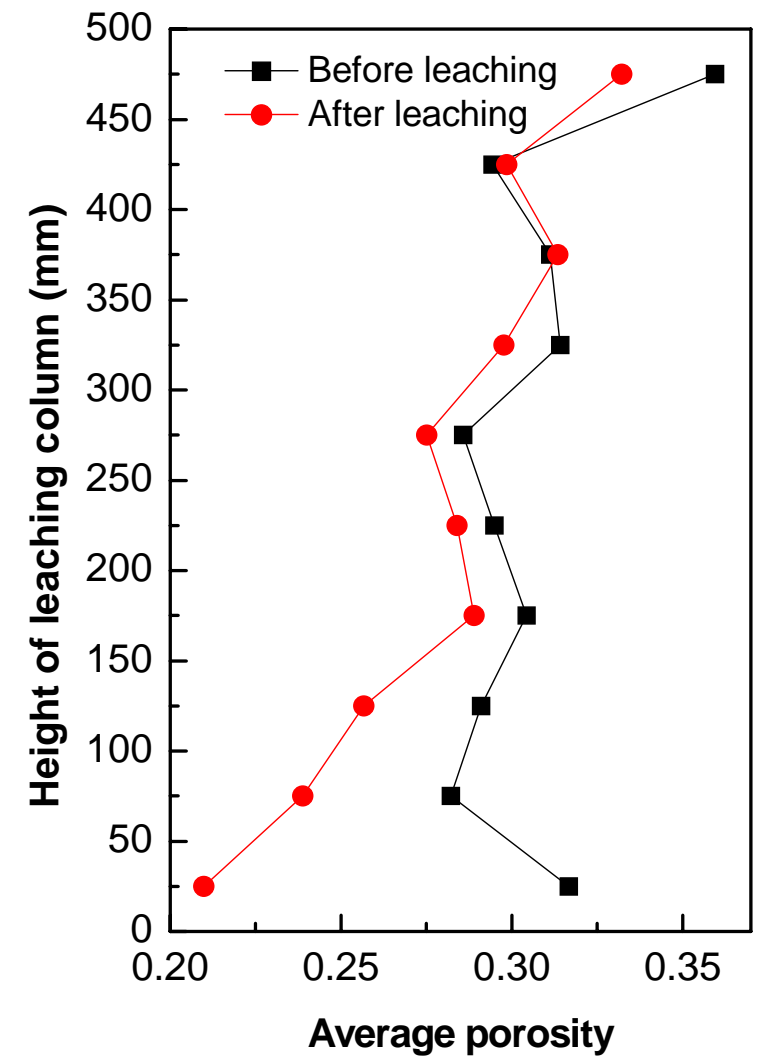

Figure 7 Comparison of the average porosities at different height before and after leaching 


\subsection{Pore size distribution}

In order to analyse the change of pore size distribution of ore granular media, taking the marked images as references, three cross-sectional images were selected respectively at the heights of $475 \mathrm{~mm}, 250 \mathrm{~mm}$ and $22 \mathrm{~mm}$ before and after leaching, shown in Figure 8. Here (a), (b) and (c) are the images before leaching; (d), (e) and (f) are the images after leaching. Their porosities are $34.03 \%, 25.32 \%, 28.66 \%, 41.03 \%, 27.12 \%$, and $17.87 \%$ respectively. Pore size distribution of each cross section can be calculated with the morphological open operation with Matlab after the images being pre-processed as mentioned previously. The results are shown in Figure 9.

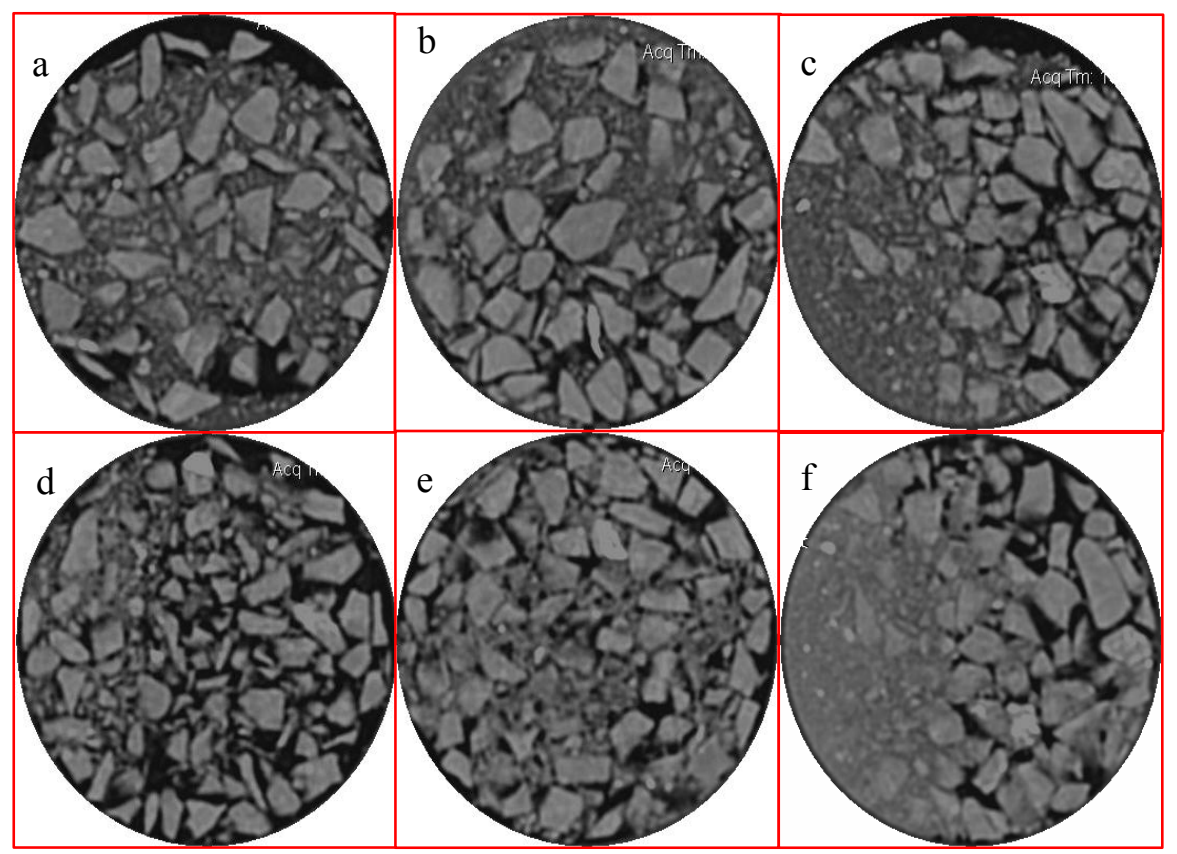

Figure 8 The typical images before and after leaching. (a) to (c) before leaching, and (d) to (f) after leaching

As can be seen from Figure 9, the pore size distribution assumes a normal distribution. The maximum pore size of each sectional image is about $5 \mathrm{~mm}$, which indicates there are some large pores. The most frequent size is about $2 \mathrm{~mm}$. At the top and middle zone, the amount of larger pores with sizes more than $4 \mathrm{~mm}$ increases while the amount of smaller pores with sizes about $1 \mathrm{~mm}$ decreases. However, at the bottom zone, the amount of larger pores reduces. It should be noted that the amount of smaller pores also decreases. It is because finer particles and chemical precipitates aggregate closely and the pores among them are so small that they were avoided during image processing. It can also be seen from Figure 8 (f), where some areas are very dense. 


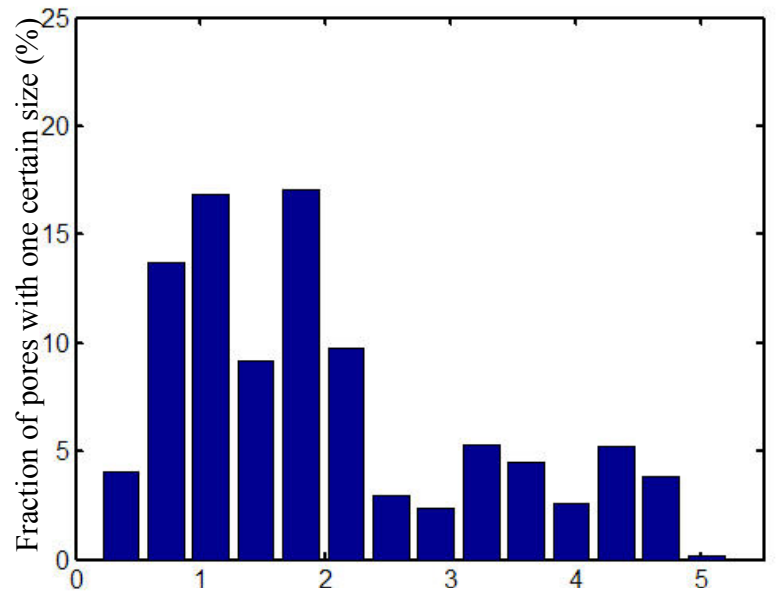

Pore size (Equivalent Spherical Diameter) (mm)

Top (before leaching, $\phi=34.03 \%$ )

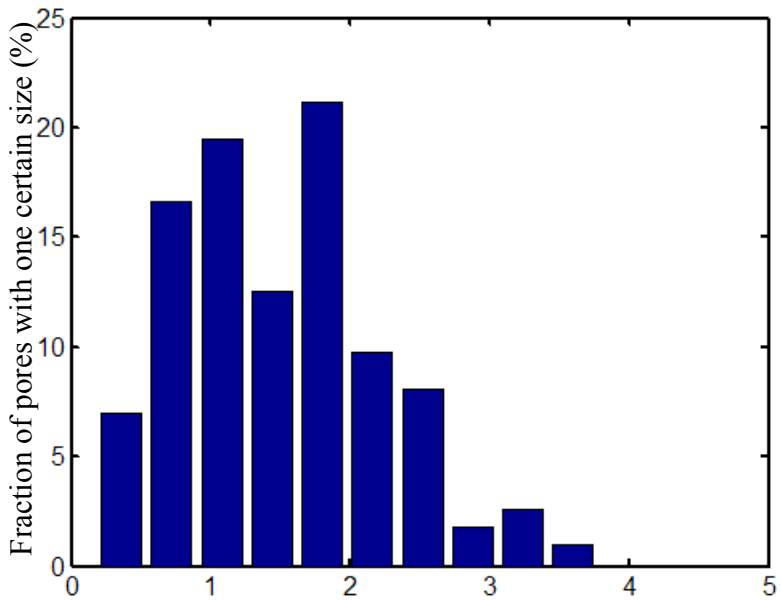

Pore size (Equivalent Spherical Diameter) (mm)

Middle (before leaching, $\phi=25.32 \%$ )

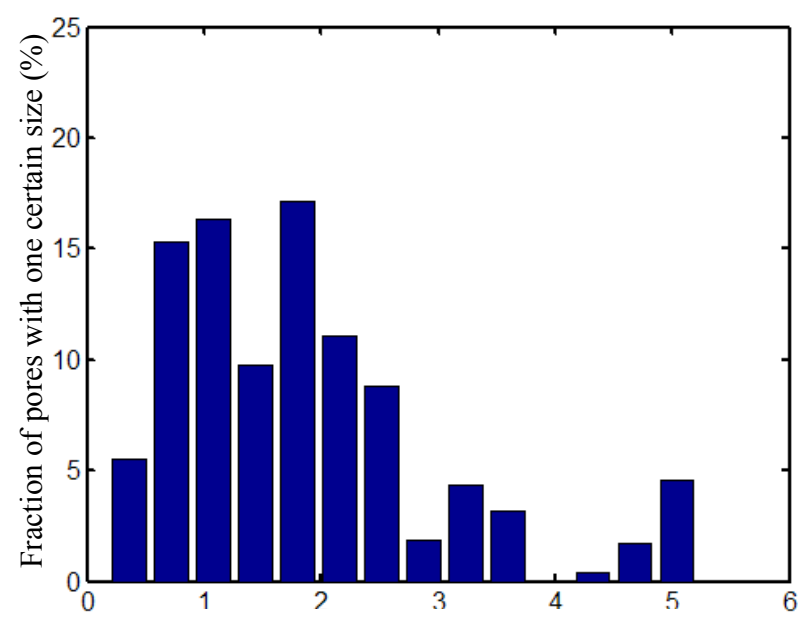

Pore size (Equivalent Spherical Diameter) (mm)

Bottom (before leaching, $\phi=28.66 \%$ )

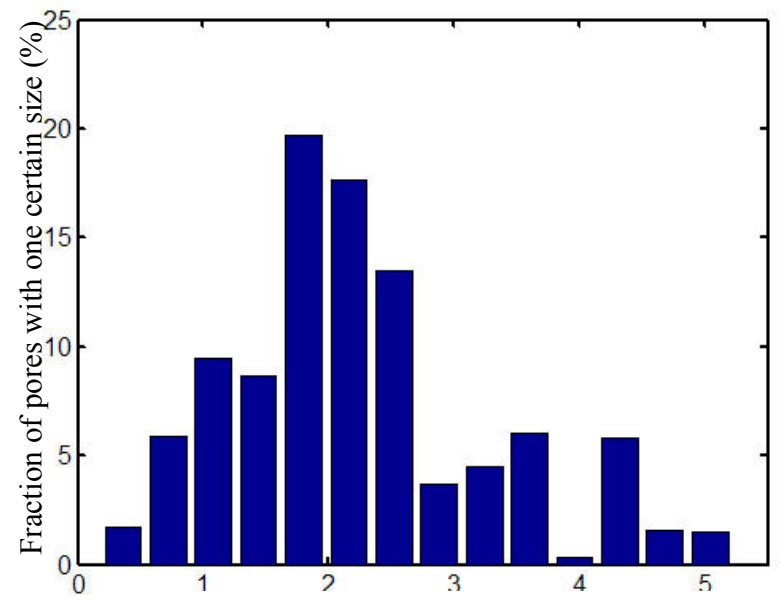

Pore size (Equivalent Spherical Diameter) (mm)

Top (after leaching, $\phi=41.03 \%$ )

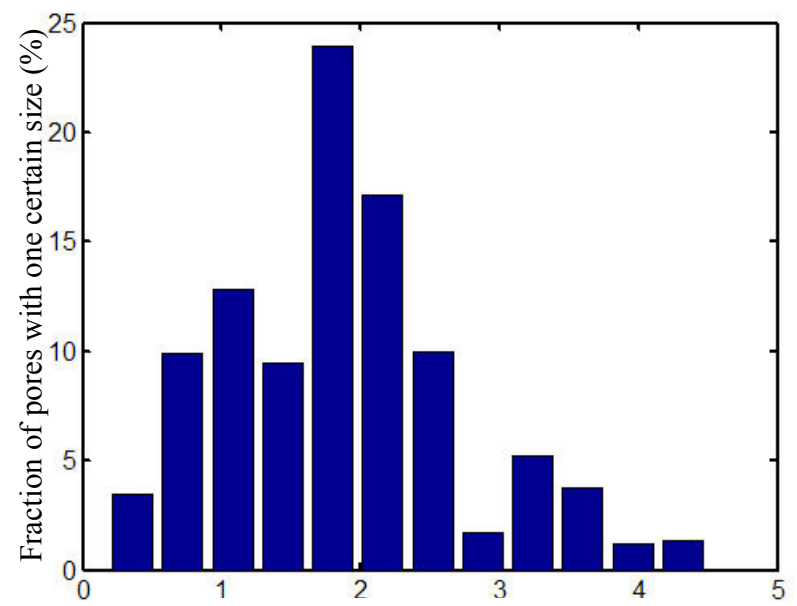

Pore size (Equivalent Spherical Diameter) $(\mathrm{mm})$

Middle (after leaching, $\phi=27.12 \%$ )

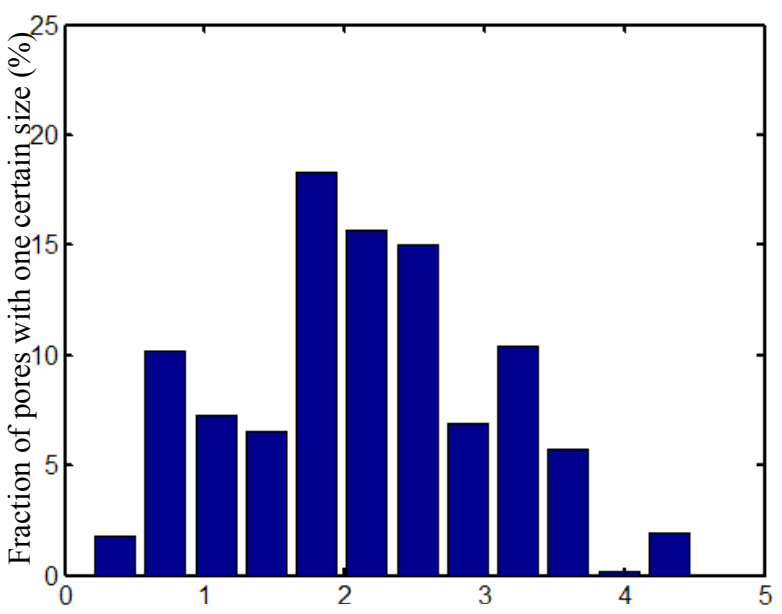

Pore size (Equivalent Spherical Diameter) (mm) Bottom (after leaching, $\phi=17.87 \%$ )

Figure 9 Pore size distributions of cross sections at different height before and after leaching 


\subsection{Connectivity}

The pore connectivity of ore granular media is an important parameter to evaluate of the performance of fluid flow inside it. However, overall connectivity is impossible to measure directly. Here, a new indirect method is adopted based on the image analysis of the obtained CT data. Neglecting the size and shape of the pores and only considering its topological structure, namely, thinning the pore into the channel with width of one pixel according to the skeletonisation algorithm, then the pore network distribution image can be obtained. Figure 10 is the pore network distribution images of top, middle and bottom zone obtained from the longitudinal profile of the whole ore packed bed shown in Figures 5 and 6 .

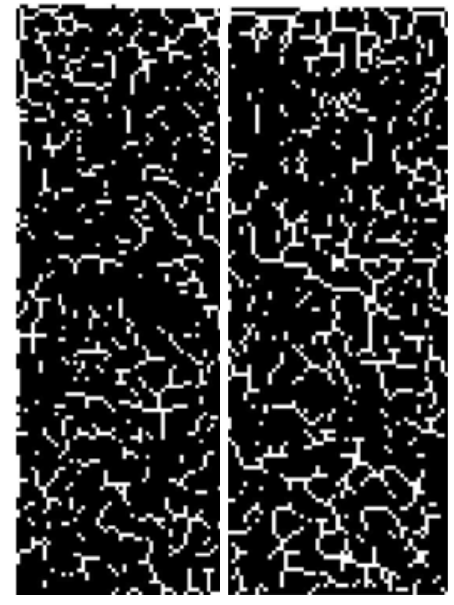

Top zone

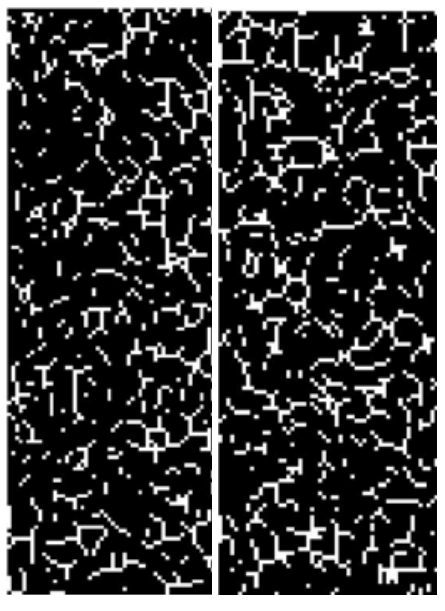

Middle zone

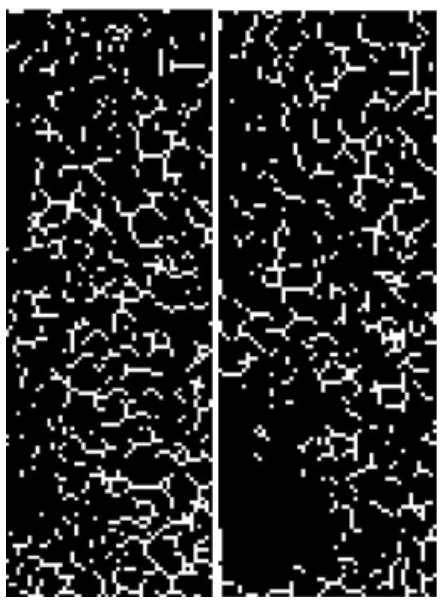

Bottom zone

Figure 10 The comparison of connectivity of the ore granular media in top, middle and bottom zone

By calculating the ratio of the total pixels of pore network to the total pixels of the profile, the pore network distribution ratio used for evaluating the pore connectivity can be obtained. The formula is given as follows:

$$
\delta=\frac{L}{S}
$$

Where:

$$
\begin{array}{lll}
\delta & = & \text { pore network distribution ratio. } \\
L & = & \text { the total pixels of pore network. } \\
S & = & \text { the total pixels of the profile. }
\end{array}
$$

Based on it, the connectivity ratio $\mathrm{n}$ is given,

$$
n=\frac{\delta_{a}}{\delta_{b}}
$$

Where:

$$
\begin{aligned}
& \delta_{a}=\quad \text { the pore network distribution ratio after leaching. } \\
& \delta_{b}=\quad \text { the pore network distribution ratio before leaching. }
\end{aligned}
$$

By calculation, the connectivity ratio of top, middle and bottom zone is $1.123,1.123$ and 0.853 respectively. Thus, it is known that both the connectivity of top and middle zone increased by $12.3 \%$, while that of the bottom zone decreased by $14.7 \%$. 


\subsection{Pore evolvement mechanism}

According to the above analysis, we can see that the porosity, pore size distribution and connectivity of the ore granular media changed along the height of the leaching column during the leaching process. It is mainly caused by the following three mechanisms:

- The first is the subsidence of the whole ore packed bed. Since the ore samples were filled into the column without any compaction operation, so the ore particles were loose and would rearrange and be compacted under the role of the gravity and hydraulic power. It is one of the main reasons for the decrease of the average porosity. In our experiment, the height of the packed ore bed decreased by $18 \mathrm{~mm}$ after 90 days leaching, shown in Figure 11.

- The second mechanism is the transportation and deposition of fine particles. From Figure 3, there includes some of fine particle in the ore sample. Once these fine particles enter into the pore network following fluid flow, they will transport continuously in the direction of low pressure and resistance (Benamar et al., 2007). When they reach the pore throat with a size less than their size, they will be trapped. At this time, these pore throats will be blocked. Particularly, when several fine particles reach one certain throat simultaneously, they may bridge together and block the pore throat.

However, if these fine particles reach the pore space with a size larger than their size, they will pass through and flow downwards.

- The third mechanism is the transportation and deposition of the chemical precipitates and colloid substance produced by the chemical and biological reactions during leaching. Just like the fine particles, they will also block the small pores or pass through large pores.

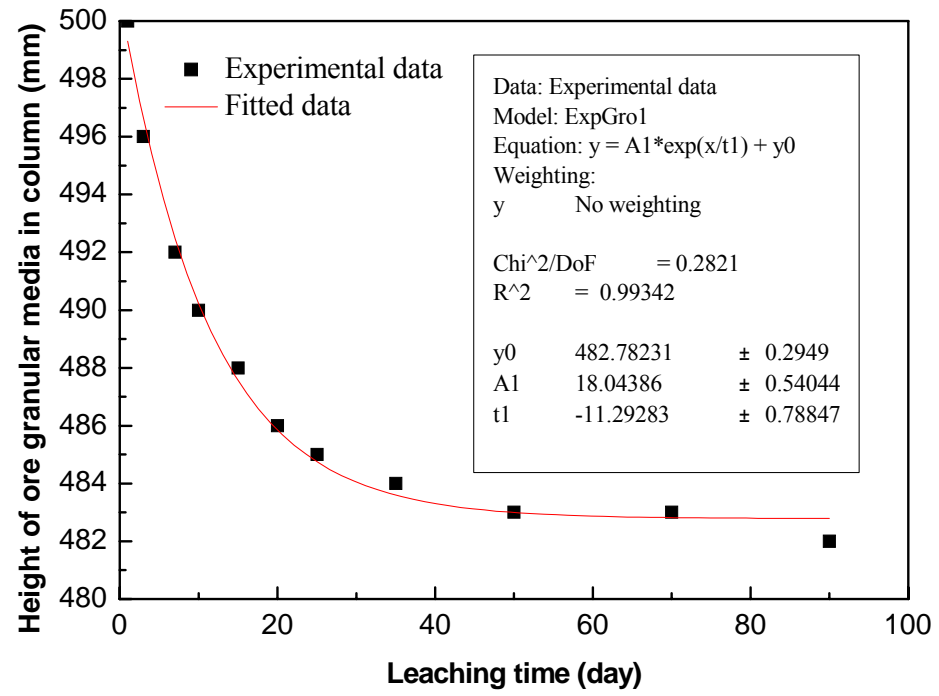

\section{Figure 11 The change of the height of ore granular media with leaching time}

The areas with many fine particles often have a low porosity before leaching, and the porosity of these areas becomes much lower after leaching, shown in Figures 5 and 6. This is mainly because the pores of fine particles are very small, so they are easy to trap those much finer particles, chemical precipitates and colloid substance. For the large pores among coarse particles, finer particles can more readily pass through, so in these areas preferential flow often occurs. In addition, part of the fine particles and precipitates at the top and middle zones are transported to the bottom zone and accumulated there, which make the pore size of these zones increase, and as a result the connectivity is improved. However, both the porosity and pore size at the bottom zone decrease so that the connectivity is greatly deteriorated.

\section{Conclusion}

Understanding the pore evolvement of ore granular media during heap or dump leaching is a fundamental basis for understanding the fluid flow inside it. A spiral X-ray CT scanner was used to explore the pore structure of a packed particle column before and after bacteria leaching of copper sulphide ores. The 
porosity, pore size and pore connectivity of the ore granular media during leaching all have spatial and temporal variability. After leaching, the average porosity decreased $2.63 \%$ and the porosity of each cross section assumed an obvious decreasing trend from top to bottom. Since the transportation and deposition of fine particles, precipitates and colloid substances, the bottom zone demonstrates the largest change. Its porosity and pore size decreased and its connectivity also decreased $14.7 \%$. The variety of these physical parameters will consequentially influence the performance of fluid flow, metal recovery ratio and leaching rate. The initial research described by this paper is suggested as being a valuable pursuit in understanding the complex mechanisms involved in optimising heap leach performance.

\section{Acknowledgements}

The authors would like to acknowledge the financial support for this work provided by the National Natural Science Foundation of China (50574099), National Key Fundamental Research and Development Program of China (2004CB619205), and the Scientific Research Fund of Hunan Provincial Education Department of China (06B052).

\section{References}

Al-Raoush, R.I. and Willson, C.S. (2005) Extraction of physically realistic pore network properties from threedimensional synchrotron X-ray microtomography images of unconsolidated porous media systems. Journal of Hydrology 300 (5), pp. 44-64.

Benamar, A., Ahfir, N.D., Wang, H.Q. and Alem, A. (2007) Particle transport in a saturated porous medium: Pore structure effects. C. R. Geoscience 339, pp. 674-681.

Hirono, T., Takahashi, M. and Nakashima, S. (2003) In situ visualization of fluid flow image within deformed rock by X-ray CT. Engineering Geology 70(7), pp. 37-46.

Kamath, J., Xu, B., Lee, S.H. and Yortsos, Y.C. (1998) Use of pore network models to interpret laboratory experiments on vugular rocks. Journal of Petroleum Science and Engineering 20(6), pp. 109-115.

Ketcham, R.A. and Carlson, W.D. (2001) Acquisition, optimization and interpretation of X-ray computed tomographic imagery: applications to the geosciences. Computers and Geosciences 27 (3), pp. 381-400.

Lin, C.L., Miller, J.D. and Garcia, C. (2005) Saturated flow characteristics in column leaching as described by LB simulation. Minerals Engineering 18(3), pp. 1045-1051.

Liu, J.S., Polak, A., Elsworth, D. and Grader, A. (2005) Dissolution-induced preferential flow in a limestone fracture. Journal of Contaminant Hydrology 78(3), pp. 53-70.

Mecke, K. and Arns, C.H. (2005) Fluids in porous media: a morphometric approach. Journal of Physics: Condensed Matter 17(2), pp. 503-534.

Nakashima, Y., Nakano, T., Nakamura, K., Uesugi, K., Tsuchiyama, A. and Ikeda, S. (2004) Three-dimensional diffusion of non-sorbing species in porous sandstone: computer simulation based on X-ray microtomography using synchrotron radiation. Journal of Contaminant Hydrology 74(3), pp. 253- 264.

Pierret, A., Capowiez, Y., Belzunces, L. and Moran, C.J. (2002) 3D reconstruction and quantification of macropores using X-ray computed tomography and image analysis. Geoderma 106(6), pp. 247-271.

Wildenschild, D., Hopmans, J.W., Vaz, C.M.P., Rivers, M.L., Rikard, D. and Christensen, B.S.B. (2002) Using X-ray computed tomography in hydrology: systems, resolutions, and limitations. Journal of Hydrology Vol. 267 (9), pp. 285-297.

Wu, A.X., Yang, B.H. and Xi, Y. (2007) Pore structure of ore granular media by computerized tomography image processing. Journal of Central South University of Technology 14(2), pp. 220-224. 